\title{
Agentes Comunitários de Saúde: agenciadores de encontros entre territórios
}

\author{
Community Health Workers: \\ promoters of interaction between territories
}

Samira Lima da Costa ${ }^{1}$

Emílio Nolasco de Carvalho ${ }^{1}$

\footnotetext{
${ }^{1}$ Departamento de Saúde, Educação e Sociedade, Universidade Federal de São Paulo, Campus Baixada Santista. Rua Silva Jardim 136, Vila Mathias. 11015-020 Santos SP. biasam@uol.com.br
}

\begin{abstract}
This article presents reflections originating from a series of meetings with community health workers over a period of ten years. It identifies the consolidation of two existential territories, which are sometimes closer and at other times more distant from each other, namely the territory of technical knowledge about health and the territory of popular knowledge about health. Starting with the analysis of some quotes from health workers and reflections which tally with the theoretical reference in the area, this paper discusses some of the dilemmas and deadlocks of access and affiliation from the perspective of some of these health workers, as well as the strategies devised on a day-to-day basis from the crossovers that take place between these two territories. It identifies the function of community health workers as frontier agents, at times acting as inventors or motivators of contact zones between the territories, and at other times acting as a representative by one territory inside the other.

Key words Community-institution relations, Technical health staff, Community health workers, Access to health services
\end{abstract}

Resumo O artigo apresenta reflexões produzidas a partir de uma série de encontros com Agentes Comunitários de Saúde, ao longo de dez anos. Identifica-se a consolidação de dois territórios existenciais, que ora se aproximam, ora se afastam: o do saber técnico em saúde e o do saber popular em saúde. A partir da análise de algumas falas de ACS e de reflexões que dialogam com o referencial teórico da área, o texto discute alguns dos dilemas e impasses do acesso e da adesão na ótica desses Agentes, bem como as estratégias cotidianamente inventadas a partir dos encontros que se dão entre esses dois territórios. Identifica-se o lugar do Agente Comunitário de Saúde como agenciador de fronteiras, atuando em alguns momentos como um inventor ou potencializador de zonas de contato entre territórios e, em outros, como um representante de um dos territórios no outro.

Palavras-chave Relações comunidade-instituição, Pessoal técnico de saúde, Agentes Comunitários de Saúde, Acesso aos serviços de Saúde 


\section{Introdução}

Este texto é o resultado de uma série de reflexões, conversas e leituras, desencadeadas por dez anos de encontros com Agentes Comunitárias de Saúde - ACS, ocorridos nas cidades de Vila Velha (ES), Vitória (ES) e Santos (SP). Tais encontros aconteceram em situações diversas, tanto de prática técnica, quanto de ensino, extensão e pesquisa. A reflexão se apoia em pesquisas realizadas nas áreas de Psicossociologia e Antropologia, que não têm a exigência de ter projetos avaliados por Comitê de Ética, como na área da saúde. No entanto, os sujeitos autorizaram, mediante assinatura de Termo de Consentimento Livre e Esclarecido, o registro dos relatos e foram tratados com nomes fictícios. Muitas dessas situações foram registradas em diários de campo, que serviram aqui como fonte para recuperar algumas dessas experiências. A partir da reflexão sobre os encontros, e apoiados na releitura dos registros, propomos pensar os modos contemporâneos de operacionalização do Sistema Único de Saúde SUS, apresentando e discutindo algumas formas como estes são produzidos (e/ou reinventados) pelos ACS nas práticas cotidianas das Unidades Básicas.

Para tanto, investimos em problematizar a produção de dois movimentos de construção do corpo, da saúde/doença, do sujeito e da vida social. O primeiro, marcado pela história dos saberes e cuidados em saúde, vem acompanhando e ocupando os espaços produzidos pela expansão e capilarização dos serviços e políticas de saúde, e chamaremos aqui de construções técnicas em saúde. O segundo - marcado por estratégias cotidianas de resolução dos conflitos, de relações de poder, de englobamentos e resistências na relação com o universo moderno de valor - vem acompanhado pelo crescimento das periferias urbanas, e chamaremos aqui de construções populares em saúde. Esses dois movimentos consolidam-se a partir da construção de territórios diferentes entre si. Em seus processos de transformação, crescimento e consolidação, identificamos a produção de fronteiras - ora móveis e maleáveis, ora imóveis e rígidas - entre ambos e propomos um olhar para o lugar do ACS, compreendendo-o como agenciador de encontros nestas fronteiras. Cabe marcar aqui que a leitura de território à qual nos referimos neste texto extrapola aquela do espaço definido geográfica ou normativamente, para identificá-lo como construção também existencial, ou seja, um campo denso de forças e laços, produtor e produzido nas redes cotidianas de composições e tensões sociais.

\section{Política, cidade e cultura}

Nas duas últimas décadas as políticas públicas de saúde brasileiras, através do SUS, consolidaram um amplo processo de expansão dos equipamentos de atenção básica em saúde. A qual deveu-se à perspectiva da inserção destes serviços nos diferentes bairros dos municípios, com o objetivo de trabalhar com a promoção e a prevenção em saúde. Neste processo, o acesso aos equipamentos do Estado tornou-se progressivamente uma realidade cotidiana para nichos sociais historicamente periféricos às políticas públicas. Nos grandes centros urbanos, a expansão da atenção básica em saúde defrontou-se com meio século de crescimento das favelas e das periferias urbanas, sem a assistência devida do Estado ${ }^{1}$.

Propomos aqui pensar a indissociabilidade dos aspectos político-culturais nestes processos de crescimento urbano e de territorialização das políticas públicas, organizada principalmente a partir da perspectiva geográfica. De que formas os valores, as verdades e as ações trazidas por esses novos equipamentos e seus investimentos civilizatórios de produção da razão, da verdade e do corpo defrontam-se com universos sociais outros, historicamente à margem dos processos de modernização? E mais: como, nos processos de territorialização geográfica dos serviços, se colocam as questões do acesso entre os territórios existenciais? Para lidar com essas questões é necessário revisitar de modo ainda que brevemente os termos politica e cultura.

Entendemos que uma problematização consistente da cultura e da política não deve restringir-se aos planos da comunicação, da percepção e das ideias sobre o mundo real e seus acontecimentos - planos estes que os tratam pelas questões enviesadas da linguagem, da representação, da ideologia, da crença e outras afins que carregam em comum a intenção de "sobrevoar" a realidade dos fatos e das ações "concretas".

É importante lembrar aqui, como fizeram muito bem Michel Foucault ${ }^{2}$ e Mikhail Bakhtin ${ }^{3}$, que as formas de produção da verdade através da razão sofreram uma grande transformação no mundo moderno que envolve não apenas os modos de relação entre a razão e a verdade, mas também os modos de produção do que vem a ser a razão e a verdade. É assim que, nos últimos cinco séculos, observa-se a desconsideração sistemática da verdade como um jogo de forças in- 
dissociável dos acontecimentos mundanos ${ }^{2}$. Este processo deslegitimou progressivamente modos outros (marginais àquilo que aqui chamamos de modernidade), tanto de produzir verdades sobre o corpo, quanto de produzir a verdade e de produzir o corpo. Isso contribui para apartar progressivamente, no mundo moderno, a verdade e o poder, a representação sobre as coisas e as próprias coisas, a ação e a linguagem, a política e a cultura.

Mas pensar esses problemas a partir do mundo europeu não é o mesmo que pensá-los fora deste. No Brasil, por exemplo, como em toda a América Latina, a legitimação das formas modernas (científicas) de produção da razão, da verdade e do corpo ocorre num período mais recente. Do mesmo modo, é também recente a marginalização das inúmeras formas outras de produção da razão, da verdade e do corpo etc., encontrando-se esse processo em plena efervescência, na vida social contemporânea.

Considerar indissociavelmente estas formas modernas de produção e as invenções que delas resultam implica toma-las de modo mais consistente e bélico no campo de forças em que estão inseridas. Em outras palavras, não se trata de investir nessas invenções como "legítimas" ou "ilegítimas”, mas sim de problematizar o processo de legitimação e as dobras que lhes são constitutivas como algo em plena efervescência. É preciso compreender, portanto, a guerra em nós que constitui essa "ontologia histórica de nós mesmos" e as guerrilhas cotidianas de nossa vida social.

Nesse percurso analítico, a própria divisão dos campos da cultura e da política, tal como produzida frequentemente nos textos acadêmicos, deve ser entendida enquanto uma das armadilhas intrínsecas à cultura moderna. Buscando problematizar os embates cotidianos produzidos nas ações de atenção básica em saúde, focamos as análises no (ainda) novo e tenso lugar do ACS.

\section{O SUS na periferia urbana e os lugares do ACS}

Segundo Schwarcz ${ }^{4}$ e Mello e Novais ${ }^{5}$, grande parte da população de periferia brasileira (urbana e rural) tinha, ainda no final do século XX, dificuldades no acesso a serviços básicos e aos meios mais elementares para a sobrevivência, sofrendo as decorrências históricas do exercício frágil da cidadania e da fraca representação do Estado.

Sendo assim, as relações constituídas nessas comunidades de periferia enredam de forma bas- tante particular os saberes propostos e produzidos em lugares considerados oficialmente como centrais: entre eles, o lugar do saber científico.

As relações entre o centro e a periferia não se constituem apenas numa construção vertical e unidirecional, como podem sugerir à primeira vista, mas enveredam caminhos em vias de mão dupla ${ }^{6,7}$. Assim, as verdades universais impostas pelo centro são assimiladas, redimensionadas, apropriadas e transformadas pela periferia, que oferece às propostas iniciais uma nova leitura. Nesta perspectiva, criam-se fronteiras móveis no interstício entre centro e periferia, onde se instalam tanto campos de relações bélicas quanto espaços de mediação.

Este fenômeno contribui para compreendermos a noção de Zona de Contato ${ }^{6}$, que pretende rever a polaridade centro-periferia (ou dominador-dominado) através de um olhar para além desta dicotomia, encontrando no espaço das relações entre as partes a elaboração e a reinvenção de sentidos, significados e identidades ${ }^{6,7}$. Aqui, sugerimos a expressão zonas de contato também para pensar os espaços de encontro entre diferentes territórios apresentados.

Nos espaços da periferia urbana são reinventadas continuamente formas diversas de produção do corpo, da verdade, da saúde-doença e da vida social. Entretanto, esta diversidade defronta-se com o processo de capilarização do SUS através dos equipamentos territoriais de saúde. E é exatamente nas zonas de contato entre esses territórios - o "das construções técnicas em saúde" e o "das construções populares em saúde" que localizamos, como agenciador oficializado, o ACS.

Pautadas na noção de cidadania participativa e nas estratégias de controle e participação social, as atuais políticas públicas em saúde defrontaram-se, desde seu início, com construções locais que ora caminham no mesmo sentido, ora desconhecem inteiramente tais políticas, ora resistem e esquivam-se das mesmas, ou ainda compõem com elas de modos diversos. Em meio a esse processo tenso de capilarização dos mecanismos do Estado ocorre a inserção progressiva dos profissionais de saúde nas comunidades, através de variados serviços e programas. A proposta traz em seu cerne a inscrição dos serviços nas comunidades primeiro pela perspectiva geográfica para, em seguida, apostar nas aproximações do ponto de vista existencial.

Nesse contexto, os diferentes modos de subjetivação nas periferias urbanas brasileiras vêm se tornando um desafio para toda e qualquer formação profissional cujas ações interventivas 
estejam voltadas para a realidade local dos sujeitos assistidos. A identificação de certo descompasso entre determinados projetos interventivos (de informação, de conscientização, de cidadanização etc.) e as construções populares que guiam as ações cotidianas dos sujeitos põe em análise a formação dos profissionais e as estratégias de ação dos próprios projetos.

Atrelados aos pilares modernos da construção da razão, da verdade e do corpo e a um projeto civilizatório à brasileira que, desde os seus primórdios, é protagonizado pelo Estado e idealizado nos circuitos intelectuais os profissionais defrontam-se agora com realidades nas quais estes pilares não ocupam um lugar central na construção da vida cotidiana ${ }^{8,9}$. Em alguns casos, ao contrário, tais pilares têm sua legitimidade, eficácia ou relevância questionadas.

Trata-se, portanto, de compreender as próprias construções técnico-científicas da saúde que originam e sustentam o SUS (suas verdades, seus valores e as configurações que o atrelam às políticas do Estado), como um dos territórios possíveis, tanto quanto as construções populares-comunitárias, destinatárias das políticas. Para tanto, é preciso uma leitura que considere tanto um quanto outro como regimes políticos de visibilidade e enunciação, tal como propõem Michel Foucault ${ }^{10}$ para o contexto europeu, ou ainda como uma tensa consolidação de universos de valor, como propõem Duarte et al. ${ }^{11}$ e Russo ${ }^{12}$ para o contexto brasileiro. Evitar utilizar qualquer um deles como parâmetro único de análise e classificação dos demais mundos possibilita visualizar melhor as formas potenciais de agenciamento, de composição e de ação interventiva. Entretanto, este é um desafio para aqueles que fundamentam sua prática a partir de uma lógica reducionista com relação aos saberes que compõem o campo do conhecimento em saúde. Neste campo "o reducionismo mais visado é o do saber biomédico, que classicamente comporta uma visão de saúde reduzida a de 'ausência de doença', privilegiando os determinantes biológicos em detrimento dos sociais na interpretação dos fenômenos saúde e doença"13.

Parece haver, entretanto, um gérmen de desestabilização dentro do próprio território das construções técnicas em saúde nas políticas do SUS, uma vez que, em certa medida, propõe e sustenta a invenção de relações de cuidado ${ }^{14-16}$ que questionam, não o lugar do saber técnico, mas seu poder nas relações com a comunidade. $\mathrm{O}$ investimento nesta invenção, que confere ao usuário e ao seu território legitimidade e (algum) poder, se produz cotidianamente em espaços variados, que se propõem a manter acesa tal discussão e se materializa na figura do ACS.

Difundido ao longo da década de 1990 como parte estrategicamente relevante nas políticas de atenção básica em saúde, o ACS tornou-se um elo essencial entre a comunidade e este serviço, contribuindo para materializar a territorialização do SUS e produzindo a inserção de uma nova perspectiva de saúde no interior das comunidades.

Neste percurso de quase duas décadas, são inevitáveis os encontros entre territórios que nem sempre falam a mesma língua. E em tais encontros, o lugar do ACS pode assumir várias formas: a de agenciador de encontros, a de intérprete de línguas, a de mediador de fronteiras, a de inventor e/ou garantidor de vias de acesso de um no outro, ou ainda a de figura catalisadora de um dos territórios.

Se por um lado o lugar das construções técnicas e a identidade de profissional de saúde conferem certo status ao ACS na comunidade, por outro lado, no confronto existencial, este mesmo discurso pode perder forças se considerarmos que, cultural e originalmente, é nas construções populares que o ACS identifica seus grupos de pertencimento (tais como família, vizinhança, amizade) e é nelas que, a priori, sua projeção e seu status ganham significado.

O processo de territorialização dos serviços de saúde propõe a desconstrução de antigas formas de poder através da municipalização da gestão, da descentralização dos espaços decisórios, da produção de protagonismo e da instituição do controle social. Entretanto, é preciso lembrar que no espaço comunitário, a reprodução de velhas formas de saber-poder somam-se às novas formas. O ACS é potencialmente uma dessas novas formas, que nasce apoiada no velho "poder do jaleco branco" ${ }^{17}$ e se projeta para dentro das relações comunitárias.

\section{Intérprete entre territórios}

Um tema bastante presente nas discussões sobre as estratégias de saúde na atenção básica é o da adesão ao tratamento, que está diretamente ligado a questões de compreensão e identificação entre linguagens.

São muitas as formas como o ACS se coloca diante dos modos de adesão e descontinuidade do tratamento. Diferentes também são as formas como os usuários se aproximam do discurso SUS/pró-saúde e assimilam as orientações inerentes aos tratamentos, produzindo desenhos e 
configurações bastante peculiares de acordo com as situações, redes e perspectivas.

Às vezes eu vejo que não é de má vontade, sabe? Não é que eles não querem fazer o que ele [o médico] manda. Que nem no grupo da hiper [hipertensão arterial], mesmo: elas entendem um pouco das coisas que ele [o médico] fala, mas nem TUDO, sabe? Daí depois eu passo lá, converso, explico direitinho, que não é pra parar o remédio quando a pressão dá baixa, que é pra tirar pressão sempre, mesmo quando tá se sentindo bem... Assim, entende? Eu não falo diferente das coisas que ele [o médico] fala, só que eu falo assim, de um jeito que dá mais pra entender, né? (Isadora, ACS de Vitória, ES).

Percebemos a condição ímpar da ACS, que pode escutar os dois territórios e perceber os ruídos na comunicação que dificultam o acesso e a adesão. Nesta fala, a arte de compor favorece o objetivo de difundir os saberes oficiais em saúde. A ACS identifica-se com as tarefas de perceber o problema e realizar intervenção sutil e eficaz, tarefas esperadas de um ACS. Suas intervenções parecem estar em consonância com o projeto SUS, sendo valorizadas e incentivadas pelas equipes dos serviços. Nessas situações, percebemos que o ACS opta por "traduzir" a linguagem de um território no outro, atuando como intérprete entre eles.

Outras vezes propõe respeitar as escolhas, conferindo ao usuário poder de autonomia sobre sua saúde e produzindo outras formas de cuidado, também sutis, como na vez que a ACS Mariana (de Santos, SP), disse ter chegado à casa de uma paciente diabética e encontrado-a comendo balas. Ao contrário do medo que sentia da repreensão do médico, frente à ACS aquela usuária não apresentou nenhum receio em admitir ter fugido da dieta, oferecendo balas à ACS. Mariana, ao avaliar o contexto e se posicionar, optou por aceitar e comer "várias" balas (diminuindo, segundo ela, a quantidade de balas que a usuária comeria), como forma de exercer o cuidado e estreitar a confiança e a cumplicidade.

Neste caso, sucumbir totalmente aos esforços normalizadores da saúde seria, para a ACS, legitimar uma surdez instituída entre os territórios do usuário e do médico/serviço. Mais que isso, seria tornar-se mais cúmplice do médico que do usuário, comprometendo o vínculo diferenciado que mantém com este último e anulando a maior parte das estratégias que lhe asseguram alguma eficiência interventiva.

O ACS caminha como um artista pelos encontros e desencontros que se produzem nas zonas de contato entre o usuário e o serviço. Consi- dera, para tanto, outros parâmetros da vida cotidiana que sejam mais relevantes, ainda que momentaneamente, do que o discurso saúde stricto sensu. Nos serviços de saúde, entretanto, estas posturas produzem certo olhar de estranhamento, podendo produzir recriminações sobre a conduta do ACS, embasados na desqualificação das construções populares em saúde e mesmo das relações afetivas nos processos de cuidado.

Intrínseca ao tema da adesão ao tratamento, encontramos tanto na fala das equipes quanto em textos escritos, a expressão "usuário rebelde" - designando usuários que não aderem ou boicotam o tratamento. Esta expressão parece ser bastante adequada para indicar o tom belicoso das relações entre o território SUS e aquele do usuário, explicitando as guerrilhas que se produzem dentro e fora dos serviços de saúde. Por "rebeldes" deve-se entender, antes de qualquer coisa, os resistentes de uma guerrilha com lados bem delimitados (dentro e fora, nós e eles etc.) e com estratégias de aliança, de confronto e de esquiva de ambas as partes, como analisado por Filgueiras et al. ${ }^{18}$.

No interior dos serviços de saúde o ACS confrontado com as metas estabelecidas, de cima para baixo, para a região assistida - é frequentemente responsabilizado ou corresponsabilizado pelo sucesso ou fracasso do tratamento, de tal forma que os "rebeldes" são justamente aqueles que põem em cheque sua competência profissional. Nas relações comunitárias, por sua vez, a maior ou menor tolerância dos ACS aos boicotes e "rebeldias" serve como um índice para o usuário, do quanto o ACS pertence -- ainda - ao mesmo território seu.

Não é raro vermos neste percurso uma recolocação do ACS nas relações comunitárias a partir de um lugar que lhe foi conferido pelo SUS no qual o seu olhar para o usuário fica desfocado, traduzido pelas lentes das construções técnicas em saúde e pelas relações viciadas de poder e de surdez que este corre o risco de produzir.

Ah, mas tem uns que eu vou te dizer, viu! Tá sabendo que não pode comer fritura e come. Tá sabendo que tem que vir tirar pressão e não vem. Tem grávida, por exemplo, que não vem no prénatal. Mas tem que vir, e elas sabem disso! Ah, eu não tenho paciência. Aí... Quem que tem que ir atrás? Eu, né! (Cláudia, ACS de Vila Velha, ES).

Tal como propomos no presente texto, uma perspectiva interessante para tais relações interterritoriais seria o encontro de territórios que se percebem legítimos e não mutuamente excludentes, em condições de diálogo e de composição 
conjunta de propostas e intervenções. Sendo assim, compreende-se que o simples deslocamento geográfico dos serviços para o interior das comunidades, embora amplie enorme e indiscutivelmente a cobertura da atenção em saúde, não significa, por si só, uma ampliação do acesso nem tampouco a consolidação da territorialização da atenção básica.

Mesmo em atendimento domiciliar, exemplo inegável de deslocamento geográfico, a equipe de saúde pode acabar levando consigo toda uma lógica de consultório - característica instituída pela ciência, que produz relações de poder hierárquico entre as construções técnicas e as construções populares em saúde - colocando-se diante do usuário como quem leva $o$ conhecimento e oferece consultas.

Ah, quando é pra ir em atendimento domiciliar, aí é diferente, né? Ali, eu que conheço. Sei das ruas, conheço todo mundo, corto caminho... Tô em casa. Agora, entrou na casa, olhou o doente... Aí é o médico que sabe, né? Olha, examina, passa remédio, manda fazer as coisas... Às vezes não dá muito certo, porque ele manda fazer uma coisa que eu sei que a pessoa não vai fazer, tipo "tirar o sal e caminhar”. Mas aí... É ele que manda, né? (Daniela, ACS de Vitória, ES).

Com frequência, os ACS reivindicam para si um lugar de poder no trato com a comunidade e seus laços densos de sociabilidade. $\mathrm{Na}$ casa e no atendimento à doença, entretanto, os mesmos ACS legitimam o poder do médico. Na fala acima, a figura do médico sustenta a lógica de consultório, uma vez que o técnico leva para o encontro seu território de construções técnicas, o que é inevitável, mas desqualifica - ou ignora, apenas - o outro ali existente.

Na mesma fala, vemos o ACS sustentando outra postura, que aqui chamaremos de lógica de tessitura: aquela que reconhece como um dado inevitável a existência de mais de um território no encontro - o do médico e o do usuário; ou o das construções técnicas e o das construções populares em saúde; ou ainda o do SUS e o da comunidade -, a legitimidade de ambos e a necessária costura/composição de seus saberes e práticas. Cada um constitui um jogo próprio de saber-poder e uma reordenação hierárquica dos sujeitos envolvidos.

Enquanto nas ruas e nas redes de convívio o ACS afirma um poder (ou contrapoder) mais eficiente que o dos técnicos, nos serviços de saúde ele reclama a falta de reconhecimento (valorativo e remunerativo) de seu trabalho.

\section{Tessituras, consultórios e poderes}

Para desenvolver melhor esta discussão, retomamos o termo usado acima, que remete a algumas velhas tensões no campo da saúde, relançando um olhar para o lugar clássico reservado ao médico e às construções técnicas na área: o lugar chamado consultório. A palavra consultório, com a mesma origem das palavras "conselho", "concílio" e "Cônsul", se relaciona com a detenção de poder e conhecimento, "lugar de consulta"19. Esta, por sua vez, seria a "ação de consultar um oráculo, consulta; decreto, deliberação, estatuto; conselho, plano, desígnio, projeto, consultor, conselheiro, olhar por, cuidar de, atender a"19.

O consultório é comumente identificado como um espaço físico cuja caricatura corresponde a uma sala com paredes brancas e equipamentos de uso médico, independente das condições de infraestrutura e de qual técnico do serviço de saúde irá usá-lo. Entretanto, este lugar extrapola os limites físicos, ao entendermos o consultório como espaço onde se encontra aquele que sabe $e$ que, portanto, oferece consultoria e faz aconselhamento, como sugere o significado da palavra. $\mathrm{Ou}$ seja: ao compreendermos o consultório como lugar do saber, percebemos com clareza o quanto a lógica de consultório extrapola os limites físicos da sala de atendimento, constituindo-se antes em um projeto de relações de poder no encontro entre os territórios já mencionados. Essa relação de poder é, muitas vezes, fomentada desde a formação dos médicos - apesar de sempre haverem experiências inovadoras ${ }^{20}$ - e de outros profissionais de saúde. Nesta perspectiva, onde quer que se dê tal encontro - seja em um ambulatório, um hospital, a rua ou o domicílio -, ali se constitui um consultório, invocando todas as forças que asseguram ao médico - e, por extensão, à equipe de saúde - tal lugar.

Neste sentido, entende-se que o projeto de relações de poder nos encontros - das construções técnicas com das construções populares em saúde - que se fundamenta nesta que aqui chamamos de "lógica de consultório" certifica ao serviço de saúde e a seus representantes o lugar de saber, sendo, portanto, um "consultor" no que se refere às questões de saúde e aos processos de adoecimento. O usuário ocupa o lugar de leigo, cujo conhecimento - ainda que seja sobre sua própria vida e saúde - é um "saber menor” e, como tal, menos qualificado, que pouco ou nada pode ajudar em suas questões de saúde e processos de adoecimento. Ao contrário, tal saber muitas vezes se coloca como um "obstáculo" às ori- 
entações e intervenções propostas pelo serviço. Por este motivo, o "bom usuário" deve assumir o lugar daquele que espera paciente, pela consulta.

O que chamamos aqui de "lógica de tessitura”, por outro lado, implica em um necessário deslocamento do lugar ocupado pelo serviço e por seus técnicos. Este deslocamento não é apenas geográfico, mas de posicionamento de saberes e poderes, compreendendo o território comunitário como, em princípio, campo alheio, acerca do qual o serviço pouco sabe, mas com o qual o usuário mantém amplas relações de saber e poder. É, então, necessário tecer continuamente composições entre saberes.

O território comunitário e o saber do usuário, nessa perspectiva, têm valor variável, situacional e conveniente no encontro das construções técnicas e das construções populares em saúde, assim como nos processos de saúde e adoecimento do usuário. Ou seja: a condição de "paciente" cede lugar à condição de cogestor de seu próprio projeto terapêutico.

Se podemos ver com frequência algum poder do ACS na comunidade e nos laços densos, durante o atendimento técnico - quando se cria virtualmente o consultório - o poder é do médico e/ ou da equipe técnica, ainda que ocorra na casa do usuário. Mas é importante evidenciar que tanto as construções técnicas quanto as populares em saúde persistem e sobrevivem em ambas lógicas, e se manifestam nos encontros entre territórios, mudando apenas a forma como os encontros acontecem a partir de uma ou de outra perspectiva, assim como o valor constitutivo dos saberes na da vida social dos envolvidos.

Nesses encontros, esta que chamamos aqui de lógica de consultório pressupõe que o lugar e o poder dos saberes precedem os encontros, enquanto que aquela outra, aqui nominada de lógica de tessitura, pressupõe que os saberes desdobram e inventam seus lugares e poderes a partir do encontro. Isso nos lembra de que, ainda que inventando formas de dar consistência e legitimidade à lógica de tessitura, os ACS em muitos momentos fazem consultoria e aconselhamentos. Ao mesmo tempo, também os técnicos dos serviços de saúde colocam-se frequentemente à mercê do que possa se produzir nos encontros.

\section{“Em nome do SUS": Alternativas bélicas na promoção e vigilância da saúde alheia}

O que significa, em uma análise mais detalhada, ser representante - falar em nome - do SUS? A atenção básica, ao territorializar as práti- cas de prevenção e promoção da saúde, leva para o interior das comunidades um projeto de revisão e redimensionamento da concepção dos serviços de saúde, desfocando a doença, descentralizando o poder e incentivando a participação social.

Apesar do proposto, o modelo integralista com foco no cuidado e prevenção em saúde não superou o modelo patocêntrico. Esses modelos co-habitam os serviços e as construções sociais, envolvendo profissionais e usuários numa trama que inventa cotidianamente os processos de adoecimento.

A descentralização da gestão implica a sociedade, convidando-a/convocando-a à gestão participativa e ao exercício do controle social, tomando como parâmetro do "correto" e do "desejável" o discurso e a prática preconizados pelo SUS. Desta forma, mesmo nos pontos que parecem tomar como premissa a proteção social e a produção de protagonismos, o "Território SUS" patina, ao transformar tais princípios em regras que determinam as relações. Muitas vezes é o ACS que identifica a necessidade de flexibilizar determinadas normas, não para dobrá-las às suas visões de mundo, mas por entendê-las como ferramentas de facilitação das relações.

A regra é igual uma peixeira, uma espada, entende? Pra usar tem de ter bom senso, sabedoria... Você só desembainha no momento certo de usar. Não é pra usar a toda hora (Joana, ACS de Vitória, ES).

Os ACS parecem compreender de modo privilegiado o poder bélico do saber técnico que apreendem, situando-se de um modo ou de outro na guerra que envolve as práticas em saúde do SUS e as de suas comunidades.

O SUS tem que me respeitar, porque sou mais velha que ele. Minha mãe aprendeu com minha avó, as coisas de doença e de saúde. Minha vó aprendeu com os antigos. Eu aprendi com minha mãe. $O$ SUS tinha que aprender um pouquinho comigo, também. E esses médicos também, são todos novinhos! Eu tenho idade, não é possível que ao menos um pouco eu não possa ensinar, né? (Fátima, ACS de Vitória, ES).

É interessante marcar a discrepância desta condição bélica e densa do saber-arma-guerra com aquela asséptica e universalista da cientificidade do corpo. Embora as construções científicas e a produção do conhecimento sejam, elas mesmas, um campo de batalhas na relação com territórios outros, construídos fora dos muros da ciência, a guerra não existe, pela própria inexistência ou insignificância desse outro. 
As construções técnicas podem, então, assumir diferentes posições na relação com as construções populares, a depender da lógica que assume. Sabemos, porém, que há uma predominância da lógica de consultório entre os representantes do território do saber técnico; ainda é difícil pensar em negociação quando há apenas um mundo legítimo: o seu próprio - todo o resto, neste caso, não passa de equívoco, falha e outras variações das velhas teorias da degenerescência.

\section{Jogos de prestígio e regimes de verdade}

Tornou-se um ponto de convergência nos estudos antropológicos a observação dos modos como o ACS maneja, junto aos usuários, o lugar de prestígio que seu ofício lhe confere. Transitando entre seu bairro e seu local de trabalho, ele aprende a transitar por diferentes circuitos de saber e por diferentes regimes de verdade. Mas isto não ocorre sem que se aprimore uma arte.

Sendo um membro a mais do território do saber técnico em saúde - tal como lhe é solicitado pelo SUS - ele entra nas casas, fiscaliza o uso de medicamentos, corrige e repreende condutas indesejáveis, tem acesso aos prontuários, facilita agendamentos. Por outro lado, sendo também integrantes do território das construções populares em saúde, alguns ACS também recomendam ir à igreja, levam maço de hortelãs pra fazer chá, dão conselhos etc. Nestes casos, ele tem o poder que a identidade de profissional da saúde lhe confere e o acesso à comunidade que sua origem e sua rede social lhe garantem.

Ah, conforme o caso, eu falo pra ir na igreja, sim. Eu não saio dando conselho de ir pra igreja pra todo mundo, mas eu conheço as pessoas, sei quem é evangélico, quem é da católica... Até da umbanda, se for o caso. Eu respeito muito, sabe? Dou conselho, Falo pra ir no lugar que a pessoa tem fé, porque a fé sempre ajuda na saúde. Sempre (Diana, ACS de Vila Velha, ES).

A consideração da dimensão religiosa do ACS é, talvez, o caminho mais explícito para pensarmos o quão indissociável pode ser a relação entre verdade e poder nas relações densas, características do cotidiano comunitário, nem sempre muito próximas das verdades científicas. Consideramos isto muito pouco no meio acadêmico - a fé e o mundo divino como força em ato, como dispositivo de revelação-ação, de verdade-poder. Melhor dizendo, consideramos bastante isto, mas por vias simplistas e demasiado etnocêntricas. Frequentemente, tratamo-la como uma limitação do sujeito, isto é, como uma "alienação" ou "crendice", tomada como um jogo de significados artificiais descolado das leis da natureza e, portanto, dos saberes técnico-científicos sobre o corpo, a saúde e a doença.

Nos relatos de experiências religiosas com os quais nos deparamos na periferia urbana (mas que pode ser visto em outros nichos sociais), as leis científicas da natureza (o encadeamento dessacralizado e necessário de causa e efeito que as fundamentam e que têm no saber dos técnicos em saúde um de seus representantes) compõem intimamente com um outro regime de verdade: a verdade-prova, na qual, entre a causa e o efeito, encontra-se um jogo agonista de forças que pode redirecionar, inverter ou anular o efeito a qualquer momento. Evangélicos, católicos, umbandistas e outros apresentaram modos diversos de compor a verdade do corpo e da saúde-doença a partir de jogos de forças que podiam tanto fortalecer os efeitos dos remédios quanto dispensálos completamente. Estes jogos conferem ao corpo, à saúde e à doença uma existência indissociável não apenas dos jogos de força mundanodivinos, mas também das dimensões moral e relacional das redes de sociabilidade locais. Tratase de um corpo e de uma saúde-doença indissociáveis das relações sociais densas e em constante produção nas ações cotidianas.

Outra questão evidenciada nos jogos de prestígio é o que se espera do ACS e do serviço. Tais expectativas se projetam nas pretensões futuras de vários dos ACS, explicitando o quanto reconhecem seu lugar como lugar menor e o quanto almejam alcançar lugares maiores, mais reconhecidos e valorados socialmente, ainda que alcançar estes lugares - ou exatamente por isso - signifique mudar progressivamente de território e de lógica. Nesse sentido, Vânia (ACS de Santos, SP) avalia que, como ainda é nova (19 anos), pretende fazer curso técnico e, em seguida o curso superior de enfermagem. Comenta ainda, como objetivo mais distante "ou até medicina!".

Interessante lembrar o que aqui chamamos de lógica de tessitura e lógica de consultório. Cada uma delas carrega em si um projeto para o encontro entre os saberes em saúde. Na prática dos serviços e nas falas das ACS, o que observamos é uma prevalência da lógica consultorial, uma vez que se observa a desqualificação do território das construções populares, ao qual o ACS pertence originalmente, e uma hipervalorização do território do saber técnico, no qual se encontra a equipe da saúde, capitaneada pelo médico. E este jogo de poder e prestígio parece alimentar, também no ACS, um desejo de se recolocar no serviço de 
saúde, ocupando lugares de maior destaque e prestígio.

\section{Para terminar, sem pretensão de concluir}

Compreendendo que as políticas do SUS vêm se implantando de forma consistente na busca das garantias constitucionais à população brasileira, entendemos ser necessário avançar a discussão nos aspectos mais sutis deste processo.

Muitas formas utilizadas pelo saber popular em saúde para compor verdades-poderes não têm lugar formal legitimado nos serviços de saúde. Nestes serviços, o caminho natural e desejável a ser trilhado pelos ACS mais competentes é o da assimilação progressiva do saber técnico em saúde, o que pressupõe, geralmente, assumir seu lugar dentro de um campo que detém não $u m$, mas $o$ saber a ser difundido e assimilado pelos usuários. Isto, por sua vez, traz como efeito a incorporação dos ranços e das dificuldades de diálogo, podendo levar o ACS a deixar de ser um transeunte entre mundos legítimos para ser apenas um representante a mais do saber técnicocientífico em saúde, infiltrado na comunidade.

Ao buscar ser um "bom profissional" nos serviços de saúde e cultivar também aí o prestígio em sua rede de sociabilidade, o ACS pode colocar em cheque justamente o que o diferencia do restante da equipe: seus laços densos com a comunidade e suas formas locais de invenção do mundo, da verdade-poder, da vida social, do corpo, da saúde-doença etc. Assim, a questão da diversidade cultural, tão preconizada pelas novas políticas públicas é, mais do que uma questão de linguagem ou uma garantia de direito, uma questão de poder.

Se por um lado espera-se dos ACS que construam a ponte sobre o abismo que se faz frequente entre o técnico em saúde e o usuário, por outro, cabe a ele justamente assimilar e legitimar progressiva e sistematicamente um modo de produzir a verdade que o distancia de suas redes densas.

O SUS traz enorme riqueza em suas formas de organização e de sociabilidade quando comparado aos modelos tradicionais. As diferentes ações dos serviços compõem entre si um cotidiano extremamente dinâmico de relações, ainda que isto possivelmente não ocorra conforme o que os técnicos de saúde desejem. Mas é preciso indagar se os diferentes territórios existenciais e suas produções de saúde e de verdade estão no centro da organização desta concepção de territorialização, ou se estaria no centro apenas a perspectiva geográfica. As reflexões deste texto indicam que os valores intrínsecos às políticas do SUS vão ao mesmo tempo de encontro e ao encontro das construções sociais dos usuários e familiares.

\section{Colaboradores}

SL Costa e EM Carvalho participaram dos encontros com Agentes Comunitários de Saúde citados no texto, bem como das análises decorrentes destes encontros, tendo igualmente trabalhado na concepção e na redação final do texto. 


\section{Referências}

1. Rocha A. Cidade cerzida: a costura da cidadania no Morro Santa Marta. Rio de Janeiro: Relume Dumará; 2000.

2. Foucault M. Microfísica do poder.11 ${ }^{\mathrm{a}}$ Edição. Rio de Janeiro: Edições Graal; 1993.

3. Bakhtin M. Cultura popular na Idade Média e no Renascimento: o contexto de François Rebelais. São Paulo: Hucitec, Annablume; 2002.

4. Schwarcz LM. Sobre Semelhanças e diferenças. In: Schwarcz LM, organizadora. História da vida privada no Brasil: contrastes da intimidade contemporânea. V. 4. São Paulo: Companhia das Letras; 1998. p. 7-11.

5. Mello JMC, Novais FA. Capitalismo tardio e sociabilidade moderna. In: Schwarcz LM, organizadora. História da vida privada no Brasil: contrastes da intimidade contemporânea. V. 4. São Paulo: Companhia das Letras; 1998. p. 559-658.

6. Pratt ML. Imperial Eyes. London, New York: Routledge; 1992.

7. Costa SL, Maciel TMFB. Os sentidos da comunidade: a memória de bairro e suas construções intergeracionais em estudos de comunidade. Arquivos Brasileiros de Psicologia 2009; 61(1):60-72.

8. Sader E, Paoli MC. Sobre "classes populares" no pensamento sociológico brasileiro. In: Cardoso RCL, organizador. A aventura antropológica: teoria e pesquisa. Rio de Janeiro: Paz e Terra; 1986.

9. Ropa D, Duarte LFD. Considerações teóricas sobre a questão do atendimento psicológico às classes trabalhadoras. In: Figueira SA, organizador. Cultura da psicanálise. Rio de Janeiro: Brasiliense; 1985. p. $178-201$

10. Foucault M. A verdade e as formas jurídicas. Rio de Janeiro: NAU Editora; 1979.

11. Duarte LFD, Barsted LL, Taulois MRO, Garcia MH. Vicissitudes e limites da conversão à cidadania nas classes populares brasileiras. Revista Brasileira de Ciências Sociais 1993; 22(1):5-19.
12. Russo JA. Os Três Sujeitos da Psiquiatria. Cadernos do IPUB 1997; 8:11-21.

13. Rozemberg B, Minayo MCS. A experiência complexa e os olhares reducionistas. Cien Saude Colet 2001; 6(1):115-123.

14. Merhy EE. Saúde: a cartografia do trabalho vivo. $3^{\text {a }}$ Edição. São Paulo: Hucitec; 2002.

15. Teixeira RR. Humanização e atenção primária à saúde. Cien Saude Colet 2005; 10(3):585-597.

16. Benevides R, Passos E. Humanização na saúde: um novo modismo? Interface Comun Saúde Educ 2005; 9(17):389-406.

17. Cukierman HL, Teixeira MO. Cotidianos de Manguinhos. Sociologias 2008; 19(10):92-105.

18. Filgueiras GB, Pereira RA, Carvalho EN. A construção social da hipertensão e do diabetes: dilemas da adesão medicamentosa no Programa de Saúde da Família. In: Rosa EM, Souza L, Avellar LZ, organizadores. A produção da Psicologia Social no ES: memórias, interfaces e compromissos. Vitória: Abrapso ES, UFES; 2008. p. 83-92.

19. Houaiss A. Dicionário da Lingua Portuguesa. Rio de Janeiro: Objetiva; 2009.

20. Backes DS, Backes MTS, Erdmann AL, Büscher A, Marchiori MT, Koerich MS. Significado da atuação da equipe da Estratégia de Saúde da Família em uma comunidade socialmente vulnerável. Cien Saude Colet 2012; 17(5):1151-1157.

Artigo apresentado em 30/04/2012

Aprovado em 17/07/1012

Versão final apresentada em 30/08/2012 